International Journal of Innovative Research in

Electrical, Electronics, Instrumentation and Control Engineering

Vol. 9, Issue 9, September 2021

DOI 10.17148/IJIREEICE.2021.9901

\title{
Design of Automatic Intensity Controller of Street Light and it's Energy Efficiency
}

\author{
Bevek Subba, Tandin Zangmo, Ugyen Zam, Aita Singh Ghalley, Phurpa Wangdi, Rinchen Wangmo \\ Department of Electronics and Communication Engineering, \\ Jigme Namgyel Engineering College, Samdrup Jongkhar, Bhutan
}

\begin{abstract}
The design of the project focuses on intensity control of the street light that saves power consumption. The concept is to control the intensity of LED bulbs used through the use of Arduino and RTC DS3231 module. The Arduino controls the light intensity of bulbs on three divided sections of time. That is from $6 \mathrm{pm}-10 \mathrm{pm}$ with full intensity (100\%), $10 \mathrm{pm}-12$ am with $50 \%$ reduction and $12 \mathrm{am}-6$ am with reduction to $25 \%$. And this proposed system can bring better result compared to existing system by reducing the unnecessary power consumption in the lighting system.
\end{abstract}

Keywords: Energy consumption, Intensity controller, LED

\section{I.INTRODUCTION}

The principle of designing a street light replacement system that uses less energy and illuminates bigger areas with the highest intensity. The provision of street lighting is one of a city's most important and costly obligations that causes enormous power losses due to the full night use of intensity. In typical cities around the world, lighting will account for $10 \%$ to $38 \%$ of the total energy bill [1]. Due to its strategic importance for economic and social stability, street lighting is of particular importance to the public authorities in developing countries. Inefficient lighting can cause money resources to be lost each year and poor lighting creates unsafe conditions. Energy efficient technology and method of design will significantly reduce street lighting costs.[2]. By introducing this initiative, street lighting intensity can be regulated and controlled automatically during the night.

In this project we planned a way to style Real Time Clock (RTC) primarily based street light control using Arduino UNO. The idea of this project is predicted on the concept of low consumption of energy. The timing is set via programming to maintain the intensity control of the bulb on the timing which is programmed.

\section{II.LITERATURE REVIEW}

LED street lights first came to use in the year 2006 in Europe. Since then the use of LED street lights has grown rapidly through the years. The main aim of paper is to run the street light on the low intensity during the off-working hours and full intensity during working hours [3]. The optimization of energy in street light and used a fixed algorithm to control the intensity of street light [4].

This system mainly focuses on intensity control of street lighting and the algorithm has provision to adjust the automatic intensity control of street light $[5,6]$. The intensity of street light is being adjusted from $0 \%$ to $100 \%$ automatically [610]. The proposed system discussed in this particular project paper is for cheaper and has a less complicated control system; it can be implemented on larger scale. Hence it gives a considerable amount of energy saving [10].

Our proposed paper mainly concerns on energy saving through the controlling of its intensity during non-working hours. The algorithm proposed an idea of reducing intensity of the street light for time span of 12am to 6am. 


\section{International Journal of Innovative Research in Electrical, Electronics, Instrumentation and Control Engineering}

Vol. 9, Issue 9, September 2021

\section{DOI 10.17148/IJIREEICE.2021.9901}

\section{III.SYSTEM MODEL}

The proposed system is as shown in the following block diagram.

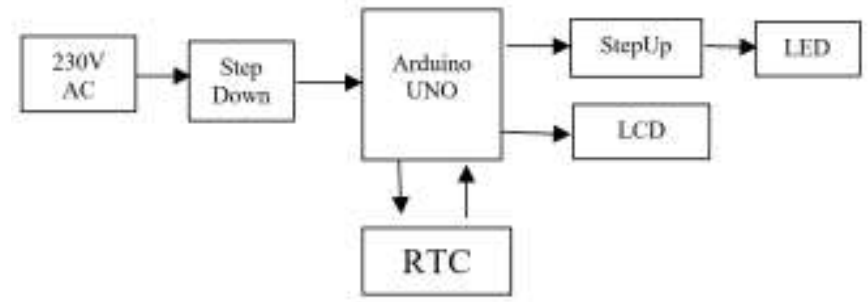

Fig.1 Block Diagram of Auto Intensity Control of Streetlight

A. Timing control

Initially, the Arduino runs in RTC mode where there are two times set in the code: the ON TIME and OFF TIME. Arduino compares the ON TIME with the RTC Module time and when they match, the LED is turned ON. After this, the Arduino waits for the OFF TIME and once the time from RTC Module matches the OFF TIME, the LED is turned OFF [4].

\section{B. Intensity control}

With the use of Arduino UNO and RTC module coding of the program is done, where by setting of the time was done in RTC module and automatic control of light intensity was controlled using the Arduino UNO. The Intensity was reduced during the no-working hours which are set above the 12 a.m. till 6 p.m. The percentage of reduction will display in the LCD. The intensity of street light was controlled by using pulse width modulation technique.

C. Power supply

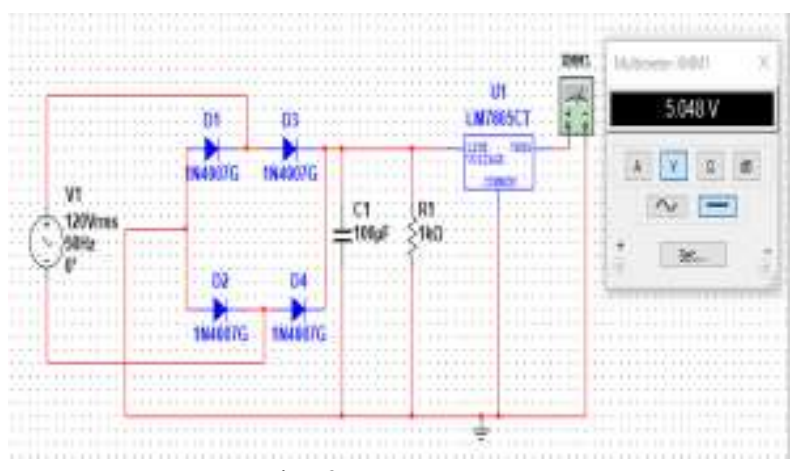

Fig. 2 Power source

The power supply circuit designed in figure 2 is fabricated on the PCB board. We have designed the circuit using power transformer [11] of (0-12) volt, capacitor(100uF), diodes, and transistor(L7805CV). The power supply is mainly to provide power to Arduino for driving the LCD to display the intensity of the light. A $230 \mathrm{v}$ ac is step down to $5 \mathrm{v}$ to drive the Arduino board.

\section{IV.ALGORITHM}

Step 1: Start the program

Step 2: Initialization:

$>\quad$ Initialization of port as input and output.

$>\quad$ Initialization of LED $=$ pin 11 and delay time was given.

$>\quad$ Initialization of LCD $=$ pin 5 .

Step 3: Checking output of LED:

$>\quad$ When the current time matches the set ON time it will automatically turn ON.

$>\quad$ When the current time matches the set OFF time it will automatically turn OFF.

$>\quad$ After the exceeding the set delay time the intensity automatically reduced.

Step 4: Checking the display of LCD:

$>\quad$ When the current time matches to ON time it displays ON. 


\section{International Journal of Innovative Research in \\ Electrical, Electronics, Instrumentation and Control Engineering}

Vol. 9, Issue 9, September 2021

\section{DOI 10.17148/IJIREEICE.2021.9901}

$>\quad$ When the current time matches to OFF time it displays OFF.

Step 5: End program.

Switching circuit is basically an analog input given in the form of algorithm. This switch can get output from components like LCD, Arduino and LED. The street light is automatically ON/OFF through the coding uploaded in Arduino board. The main components are Arduino to control the intensity of light through the communication between RTC module and Arduino.

\section{V.SIMULATION AND RESULT}

The simulation performed in Proteus software gives the detail description about working of the system. To find out energy saved after implementing this circuits on a 9W LED is calculated for one hour i.e.,

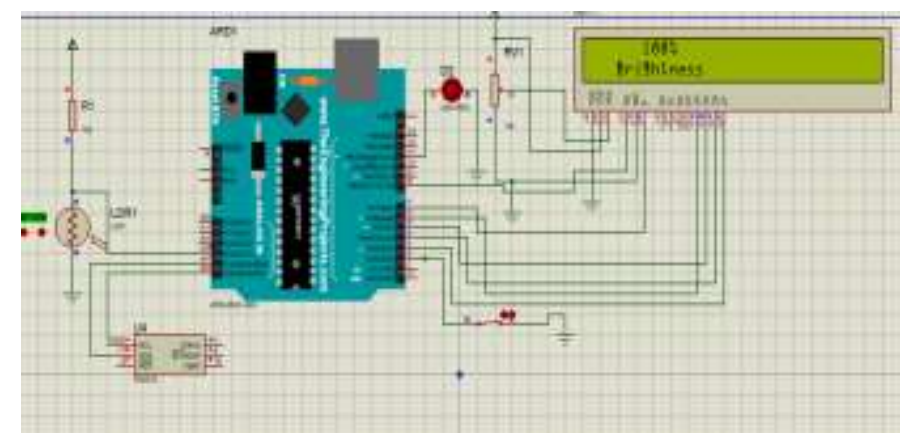

Fig. 3 Simulation

For implementing any system, it has to economically benefit and thus, it is necessary to analysis its financial aspect. Since we are controlling the intensity as per the required hours, energy consumption is reduced. For the analysis, the mostly used room at night was selected.

A. Energy consumption before implementation.

i. $\quad$ Energy consumption $=$ no. of bulb $*$ rating $*$ time $=1 * 9 \mathrm{w} * 12 \mathrm{hr}=0.108 \mathrm{kwh}$

Total Energy consumption per year $=0.108 * 365=39.42 \mathrm{kwh}$

ii. Brightness calculation $=0.50 \mathrm{lux}$

B. Energy consumption after implementation.

i.Energy consumption with full intensity $(6 \mathrm{pm}$ to $10 \mathrm{pm})=$ no. of bulb $*$ power rating $*$ time

ii.Brightness calculated $=0.50$ lux (calculated from lux meter)

$$
=1 * 9 \mathrm{w} * 4 \mathrm{hr}=0.036 \mathrm{kwh}
$$

iii.Energy consumption with $50 \%$ intensity $(10 \mathrm{pm}$ to $12 \mathrm{am})=$ no. of bulb $*$ power rating $*$ time

$$
=1 * 5.85 \mathrm{w} * 2 \mathrm{hr}=0.0117 \mathrm{kwh}
$$

iv.Brightness calculated $=0.41$ lux (calculated from lux meter)

v.Energy consumption with $25 \%$ of intensity $(12 \mathrm{am}$ to $6 \mathrm{am})=$ no. of bulb $*$ power rating $*$ time

$$
=1 * 5.775 \mathrm{w} * 6 \mathrm{hr}=0.03465 \mathrm{kwh}
$$

vi.Brightness calculated $=0.23$ lux(calculated from lux meter)

Total Energy consumption $=0.036+0.0117+0.03465=0.08235 \mathrm{kwh}$

Total Energy consumption per year $=0.08235 * 365=30.05775 \mathrm{kwh}$

Comparison Energy consumed before implementation - Energy consumed after implementation $=39.42-30.05775=9.36225 \mathrm{kwh}$ (Annually saved energy)

Total Energy saved in a year in percentage $=$

$$
\frac{\text { Energy saved in a year }}{\text { Energy consumed before implementation }} * 100=\frac{9.36}{39.42} * 100=23.7 \%
$$




\section{International Journal of Innovative Research in Electrical, Electronics, Instrumentation and Control Engineering}

Vol. 9, Issue 9, September 2021

\section{DOI 10.17148/IJIREEICE.2021.9901}

\section{CONCLUSION}

The reduction in the power intensity of light lowers the power consumption. This will lead to energy consumption. Using LED bulbs require much less power input than the CFL or Incandescent lights bulbs. It would easily be installed as circuit used by system as the size is compact which can be merged with long and bulky hardware of LED Street light. The lighting control system is designed to provide the right amount of light where and when it is needed. The lighting control can be performed automatically through programming.

In this project Arduino UNO based model using RTC Module is developed which can power the street automatically and accordingly reduce the intensity. This paper elaborates the design and construction of automatic light control system circuit. Circuit works properly to control intensity of lighting through use of Arduino UNO microcontroller. From the calculation, $9.36 \mathrm{kWh}$ of energy was saved by controlling the intensity of the light. $23.7 \%$ of the energy can be saved by implementing the light intensity controlling mechanism.

\section{REFERENCES}

[1] D. R. Khade, N. V. Gajane, S. N. Gawade and R. A. Metri, "Intensity controller of LED street lights," 2017 International Conference on Circuit ,Power and Computing Technologies (ICCPCT), 2017, pp. 1-4.

[2] Y. W. Bai and Y.T. Ku," Automatic room light intensity detection and control using a microprocessor and light sensors," IEEE Transactions on Consumer Electronics, Vol. 54, No. 3, 2008, pp. 1173-1176.

[3] C. Juang, Y.C. Chuang and Y. L. Ke," Design of close- loop buck-boost converter for led driver circuit," industrial and commercial power system technical conference (I \& CPS), 2011 IEEE, vol. 1, no. 6, May 2011, pp. 1-5.

[4] M. D. Vijay, K. Shah, G. Bhuvaneswari and B. Singh,” LED based street lighting system with Automatic Intensity Control using Solar PV,” IEEE AIS joint Industrial petroleum and chemical industry conference (ICPSPCIC), 2015, pp. 197-202

[5] B. K. Chaitanya, R. Suresh, A. S. K. Kaushik, M. Mahesh, C. Kala and K. S. R. Kumar, "Automation of Street Lights using Arduino \& NI Lab VIEW," 2015 IEEE UP Section Conference on Electrical Computer and Electronics (UPCON), 2015, pp. 1-3, doi: 10.1109/UPCON.2015.7456689.

[6] A. Lavric, V. Popa and I. Finis, “The Design of Street Lighting Monitoring Control System” International conference and exposition on Electrical and Power engineering, October 2012, pp. 314-317.

[7] M. A. Wazed, N. Nafis, M. T. Islam \& A. S. M. Sayen, "Design and Fabrication of Automatic Street Light Control System, Engineering eTransaction, vol. 5, No. 1, June 2010, pp. 27-34.

[8] M. Popa and C. Cepisca, "Energy consumption saving solution based on intelligent street light control system,” U.P.B. Sci. Bull., Vol. 73, April 2011, pp. 297-308.

[9] M. Vaghela, H. Shah, H. Jayswal and H. Patel, “Arduino based Auto Street Intensity Controller,” Inventi Rapid: Embedded systems, Vol. 2017, Issue 3, 2017, pp. 1-4.

[10] O. Rudrawar, S. Daga, J. R. Chadha and P. S. Kulkarmi, "Smart Street Lighting System with Light Intensity Control using Power Electronics," Technologies for Smart-City Energy Security and Power, 2018, pp. 1-5.

[11] M. S. Badad, "Step Down Transformer - Working Principle, Equation, Types, Advantages and Disadvantages,” Retrieved from https://electrical fundblog.com>. 